\title{
The daily variation of the concentration of suspended particles in the surface layer of the atmosphere of the village Berezovka (Krasnoyarsk region)
}

E. N. Zavorueva, V. V. Zavoruev, Yu. L. Lipovka

E. N. Zavorueva, V. V. Zavoruev, Yu. L. Lipovka, "The daily variation of the concentration of suspended particles in the surface layer of the atmosphere of the village Berezovka (Krasnoyarsk region)," Proc. SPIE 10833, 24th International Symposium on Atmospheric and Ocean Optics: Atmospheric Physics, 108336K (13 December 2018); doi: 10.1117/12.2505157

Event: XXIV International Symposium, Atmospheric and Ocean Optics, Atmospheric Physics, 2018, Tomsk, Russian Federation 


\title{
The daily variation of the concentration of suspended particles in the surface layer of the atmosphere of the village Berezovka (Krasnoyarsk region)
}

\author{
E.N. Zavorueva ${ }^{1}$, V.V. Zavoruev ${ }^{1,2}$, Yu.L. Lipovka ${ }^{1}$ \\ ${ }^{1}$ Siberian federal university, 79 Svobodny pr., 660041 Krasnoyarsk, Russia; \\ ${ }^{2}$ Institute of computational modeling SB RAS, Akademgorodok, 660036 Krasnoyarsk, Russia
}

\begin{abstract}
$\mathrm{PM}_{10}$ concentrations in the surface layer of the atmosphere of Berezovka are 2-3 times higher in winter than in summer. The daily variation of suspended particle concentrations is characterized by two maxima and two minima. It is more pronounced in January and February than in June and July. Winter maxima are mainly due to the time intervals of 9-11 and 19-21 hours, and summer-on 9-11 and 22-23 h. Minima are due to 4-5 and 15-17 $\mathrm{h}$ in winter, and in summer - 4-6 and 14-18 $\mathrm{h}$. The daily variation of PM2.5 is similar to the daily variation of $\mathrm{PM}_{10}$ in winter. The difference is that the concentration of $\mathrm{PM}_{2,5}$ increases to values that are significantly higher in the evening than in the afternoon. Air pollution is associated with coal heating of individual houses in the village and the daily variation of the concentration of PM is determined by the heating regime of dwellings.
\end{abstract}

Keywords: $\mathrm{PM}_{2,5}, \mathrm{PM}_{10}$, the daily variation, the village of Berezovka, autonomous sources of heat supply

\section{INTRODUCTION}

The problem of air pollution of cities and small settlements by suspended particles (particulate matter - (PM)) is relevant in the world [1-3]. To some extent, this is due to the fact that regardless of the nature of all $\mathbf{P M}_{2,5}$ related to carcinogens [3].

The Russian Federal structure (Roshydromet) which is authorized to monitor the air environment has been measuring the concentration of suspended substances for decades (analogue of total suspended particles (TSP)). At the same time since 1987 almost all countries have moved to the measurement of PM concentration on the recommendation of the environmental protection Agency.

In Russia only the last few years official monitoring of the PM in some cities began to be carried out by the forces of the subjects of the federation. Since the end of 2011 the Center of implementation of measures for nature and environmental protection (CIMNandEP) of Krasnoyarsk region began to carry out continuous measurements of the $\mathrm{PM}_{10}$ concentration at its monitoring posts for the first time. Since November of 2017 devices have been installed at the posts of the CIMNandEP with the help of which it became possible to measure the concentration of $\mathrm{PM}_{2,5}$.

A number of works have been devoted to revealing the regularities of the diurnal variation of suspended particles in the atmosphere of Russian cities and in regions of background stations for example [4-7]. At the same time attention is not paid to the investigation of such regularities in the air of small territorial settlements. The dynamics of pollution of the atmosphere in settlements of Siberia is practically not investigated. In most Siberian villages houses are heated by autonomous sources of heat supply (ASHS) using hydrocarbon fuel. In this paper the term ASHS refers to the sources of thermal energy of individual residential buildings that are not related to central heat supply systems. Furnaces and boilers are predominantly used as ASHS. Coal and firewood are used as a hydrocarbon fuel.

This work is devoted to the investigation of the regularities of pollution in the village of Berezovka which is located on the Yenisei River, east of the city of Krasnoyarsk, directly outside the city. In this village the individual houses with coal ASHS predominate among residential buildings.

\section{THE DATA USED}

The scheme of location of automated monitoring stations (AMS) for air pollution and the measurement results are presented on the site http://krasecology.ru.

24th International Symposium on Atmospheric and Ocean Optics: Atmospheric Physics, edited by Gennadii G. Matvienko, Oleg A. Romanovskii, Proc. of SPIE Vol. 10833, 108336K

(C) 2018 SPIE · CCC code: $0277-786 X / 18 / \$ 18 \cdot$ doi: $10.1117 / 12.2505157$ 


\section{APPARATUS FOR MEASURING CONCENTRATION OF AEROSOL PARTICLES}

The following equipment is used for measuring the concentration of the PM on the posts of CIMNandEP.

A combined semi-automatic dust meter OMPN-10,0 was used to measure the concentration of $\mathrm{PM}_{10}$ of different origin and chemical composition in atmospheric air.

The principle of the dust is based on the complex use of optical and gravimetric methods and consists of detecting scattered radiation by an optical sensor and parallel forced pumping of the analyzed air sample through an AFA-VP-10 analytical aerosol filter (AFA-VP-20).

The optical unit provides a measurement of the concentration of suspended particles in continuous conditions in the standard RM-10 (when using the appropriate impactor).

The beam of the He-Ne laser illuminates the measuring chamber through which the analyzed air sample is pumped. Aerosol particles in the beam trajectory scatter light. Direct radiation gets into light trap, which is an absolutely black body, in which it is completely absorbed. The photodetector registers the radiation at an angle of $90^{\circ}$, whose integral values of intensity are proportional to the concentration of aerosol particles.

When exceeding the values of the mass concentration of aerosol particles of the alarm threshold set on the optical unit, electroactivator automatically turns and sampled air analyzed on an analytical filter. After that in the laboratory determination of the mass concentration of aerosol particles by gravimetric method for correct the calibration characteristics of the optical Assembly is conducted.

The model dust analyzers VAM-1020 ("Met One Instruments Inc.", USA) is used to measure atmospheric air concentrations of $\mathrm{PM}_{2,5}$ and $\mathrm{PM}_{10}$. The principle of the Met One dust analyzer is radioisotope based on the absorption of $\beta$-radiation by particles of dust deposited on the filter tape. The isotope $C^{14}$ is used as a source of $\beta$-radiation. Dust is deposited on the filter belt as a result of pumping the air sample with a pump. Measurement of the absorption of radiation is carried out with the help of a built-in detector - an organic scintillator with a photoelectric multiplier.

\section{RESULTS AND DISCUSSION}

In the structure of the housing of the village Berezovka individual houses are dominated which are used for heating brown coal. It is obvious that these autonomous sources of heat supply contribute to the pollution of the surface layer of the atmosphere in winter. The data presented in Table 1 are consistent with this statement. In all cases, except July of 2016, the average monthly aerosol concentration was 2-3 times lower in summer than in winter. It should be noted that the $\mathrm{PM}_{10}$ content in the air in January and February of 2013-2015 is higher than the maximum permissible concentration daily average which is $0,06 \mathrm{mg} / \mathrm{m}^{3}$.

Table 1. Average monthly concentrations of $\mathrm{PM}_{10}\left(\mathrm{mg} / \mathrm{m}^{3}\right)$ in the surface layer of the atmosphere in the village of Berezovka in the winter and summer months of 2013-2016

\begin{tabular}{|c|c|c|c|c|c|}
\hline \multirow{2}{*}{ Year } & \multicolumn{2}{|c|}{ Winter } & \multicolumn{3}{c|}{ Summer } \\
\cline { 2 - 6 } & January & February & June & July & August \\
\hline 2013 & $0,072 \pm 0,004$ & $0,071 \pm 0,004$ & $0,028 \pm 0,0004$ & $0,039 \pm 0,0010$ & $0,046 \pm 0,0030$ \\
\hline 2014 & $0,061 \pm 0,003$ & $0,083 \pm 0,004$ & $0,024 \pm 0,0008$ & $0,025 \pm 0,0009$ & $0,030 \pm 0,0010$ \\
\hline 2015 & & $0,083 \pm 0,004$ & $0,032 \pm 0,0006$ & $0,028 \pm 0,0008$ & $0,015 \pm 0,0005$ \\
\hline 2016 & & & $0,029 \pm 0,0009$ & $0,108 \pm 0,0040$ & $0,040 \pm 0,0010$ \\
\hline
\end{tabular}

The results of the OMPN-10.0 dust meter measurement averaged for each hour were used to plot the daily variation graphs of the $\mathrm{PM}_{10}$ concentration. Each point of the graph is obtained as a result of statistical processing from 84-93 measurements.

The daily variation of concentrations of suspended particles is characterized by two maxima and two minima in winter (Fig. 1). The maximums mainly are at the time intervals 9-11 and 19-21 hours and the minima - at 4-5 and 15-17 hours. 


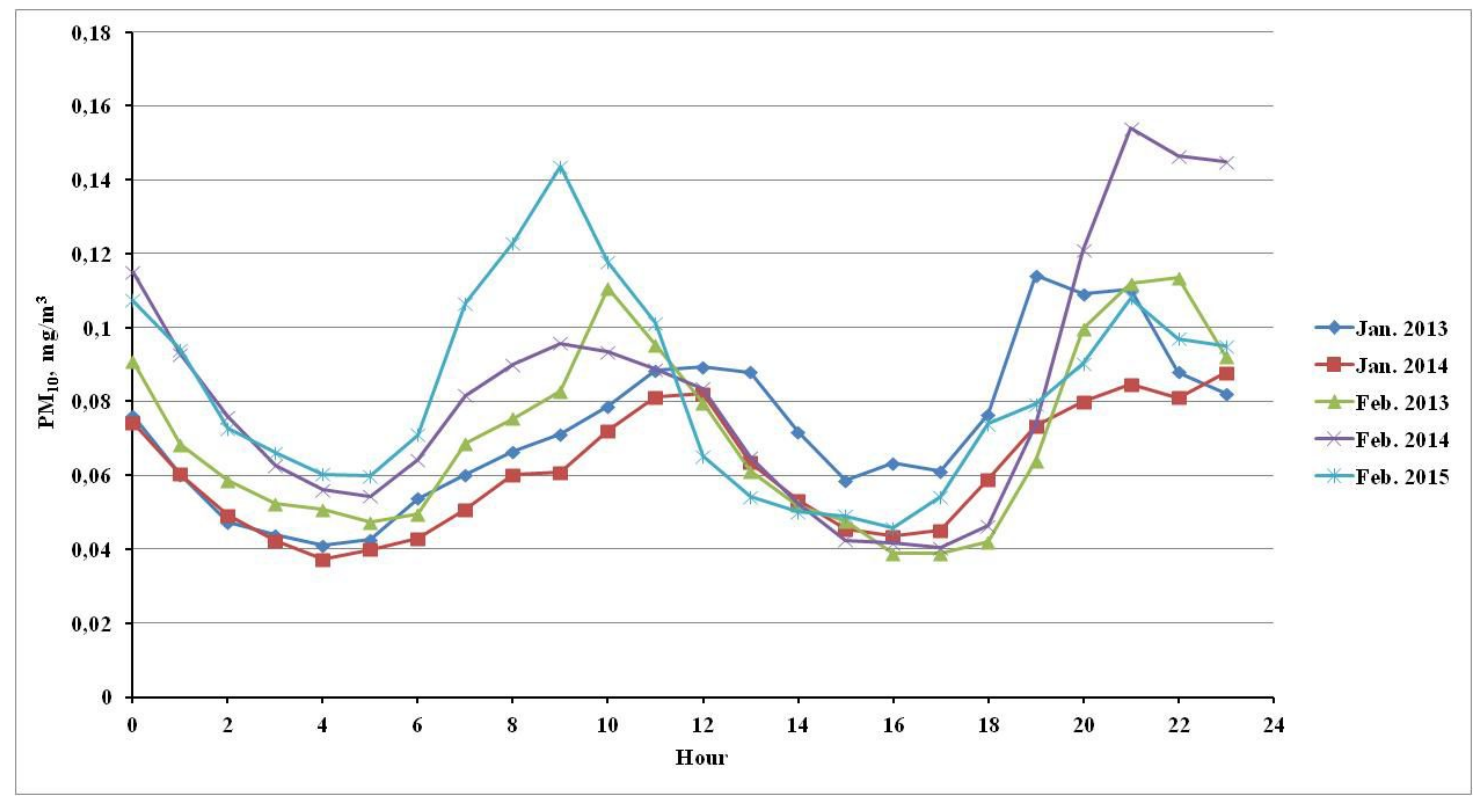

Figure 1. Daily variation of $\mathrm{PM}_{10}$ concentration in January and February of 2013-2015

The dependence presented in Fig. 1 significantly different from the similar relationship obtained for residential areas of Moscow (figure 3, works [4]), both by the number of maxima and minima and by the value of variations in concentrations of $\mathrm{PM}_{10}$.

The summer daily variation of suspended particle concentrations is characterized by two maxima and two minima (Fig. 2). Maxima are mainly in the time intervals $9-11$ and 22-24 h and the minima - 4-6 and 14-18 h. A similar shape of the diurnal variation of aerosol was obtained for the Moscow region [1].

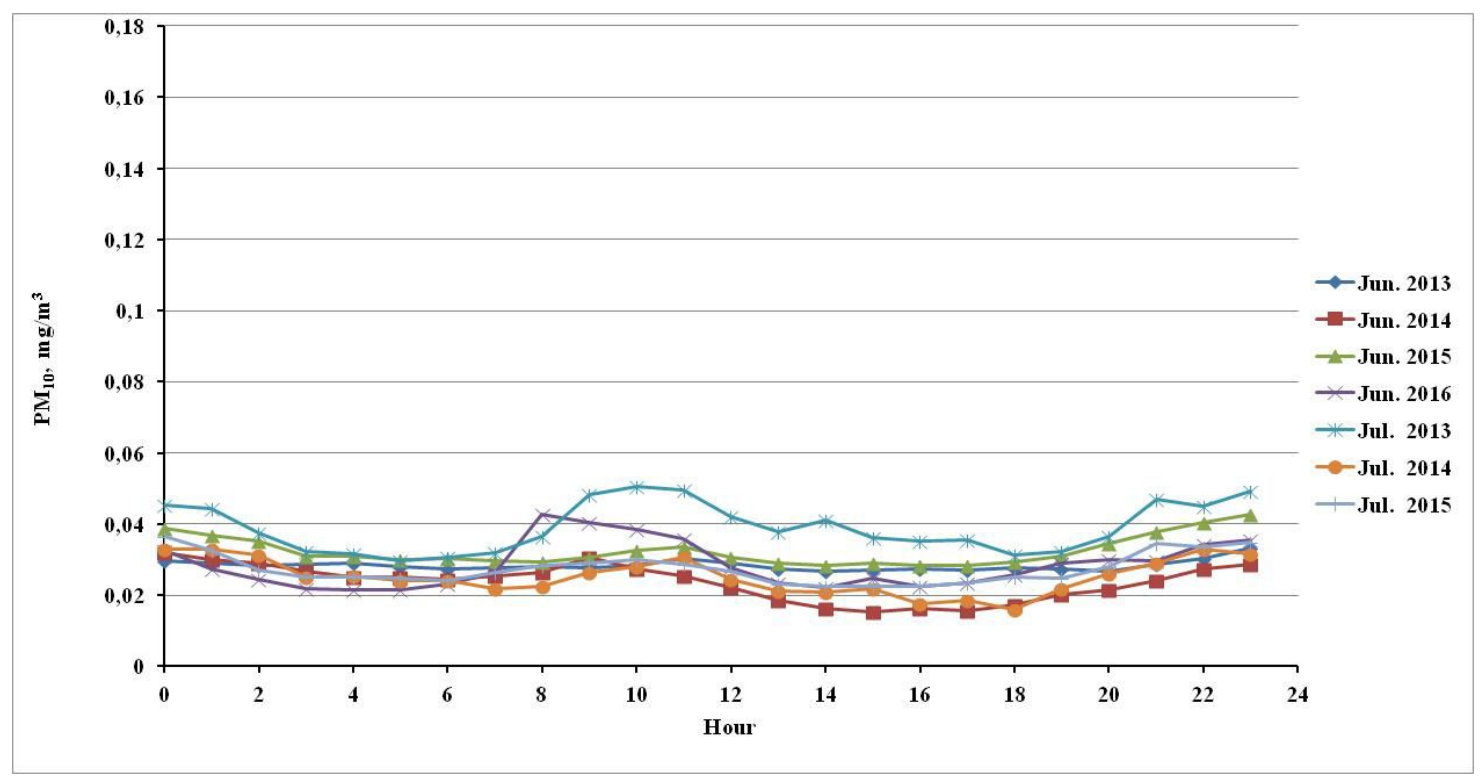

Figure 2. Daily variation of $\mathrm{PM}_{10}$ concentration in June and July of 2013-2016

In July of 2016 the average monthly concentration of $\mathrm{PM}_{10}$ was the highest (Table 1). Significant pollution of the surface layer of the atmosphere was observed in the second half of the month (Fig. 3). 


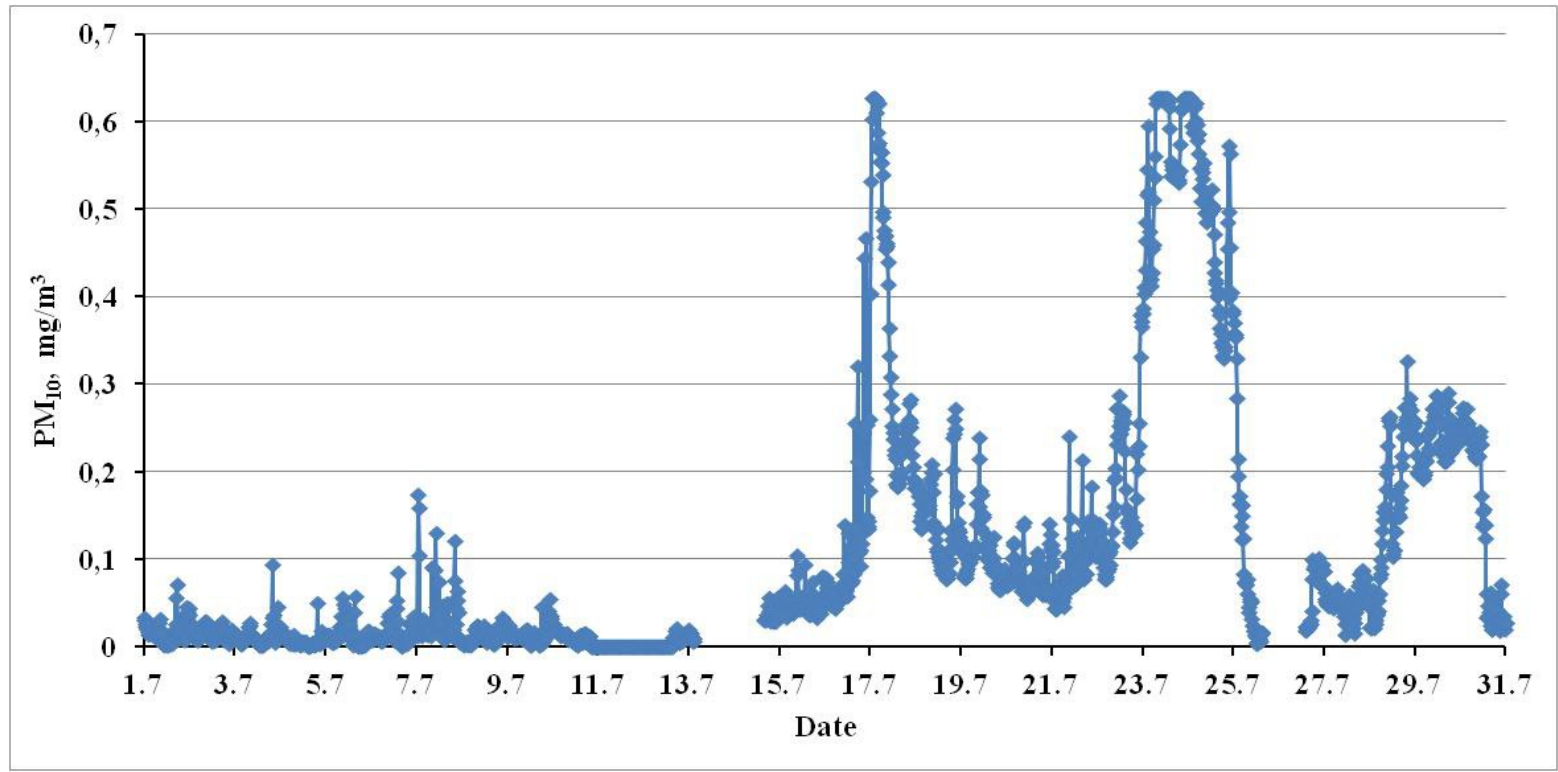

Figure 3. Dynamics of $\mathrm{PM}_{10}$ concentration in July of 2016

The regime of UMC of the first degree is announced each month in Krasnoyarsk in July. So in 2013 the period of UMC was July 16-29; in 2014 - 5-6, 11-14, 21-23 July; in 2015 - July 17-20; 2016 - July 17-25. In 2013-2015 $\mathrm{PM}_{10}$ concentrations varied in the range of $0-0,2 \mathrm{mg} / \mathrm{m}^{3}$ in this month with single "bursts" during 3-4 hours to $0,3 \mathrm{mg} / \mathrm{m}^{3}$. The number of such "bursts" did not exceed four per month. However in July of 2016 the concentration of suspended particles was more than $0,6 \mathrm{mg} / \mathrm{m}^{3}$ during $24-48$ hours. Such pollution was during the UMC period and outside this period a continuous pollution of the atmosphere was of up to $0,3 \mathrm{mg} / \mathrm{m}^{3}$ in July $29-31$.

The daily variation of suspended particles in July 2016 (Fig. 4) is not characterized by reliable maxima or minima unlike similar dependencies calculated for June and August.

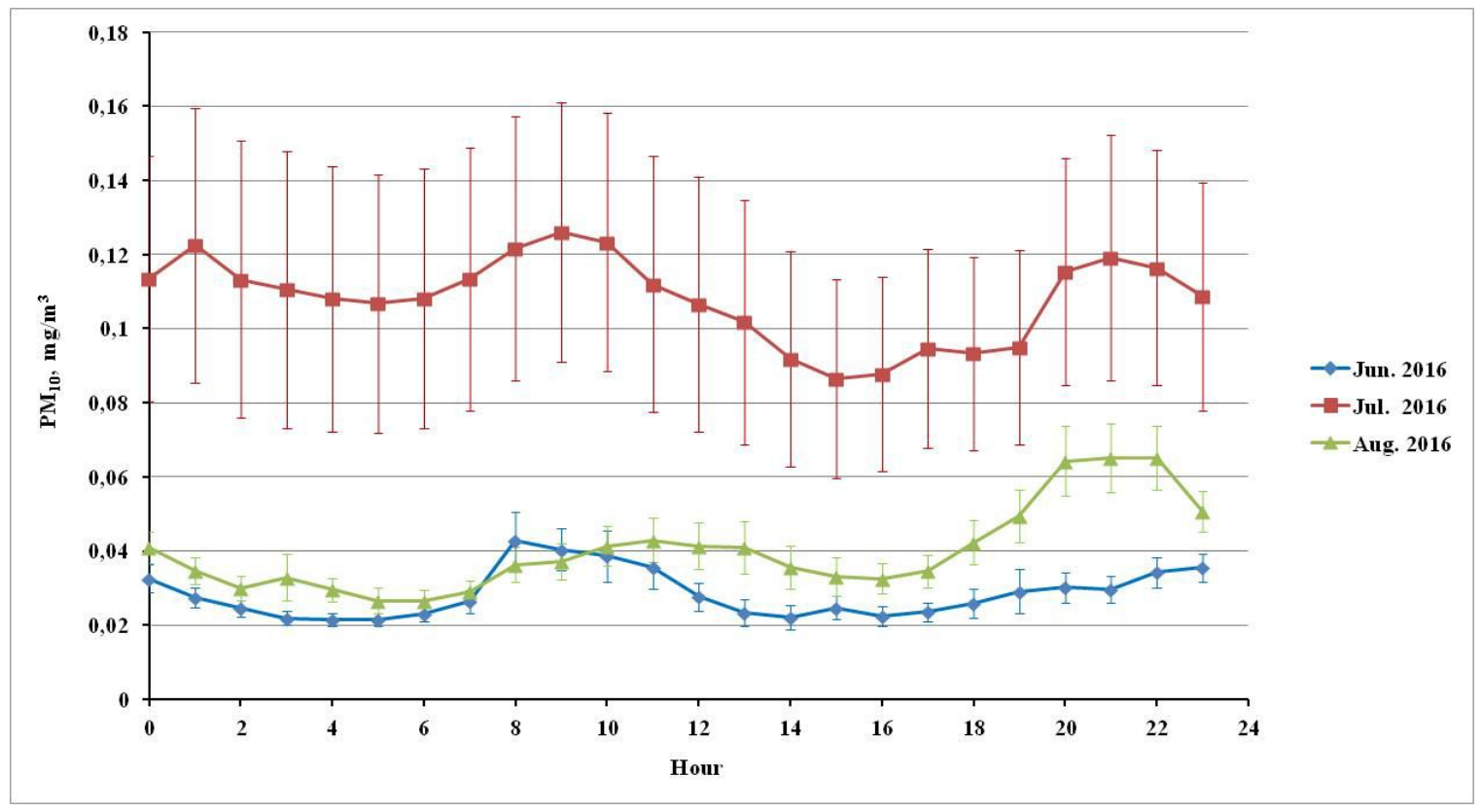

Figure 4. The daily variation of $\mathrm{PM}_{10}$ concentration in the summer of 2016 
The data presented above show that the pollution of the surface layer of the atmosphere in the village of Berezovka in the winter period is determined by emissions from autonomous sources of heat supply (coal furnaces and coal boilers). In addition these emissions determine the daily variation of concentration of $\mathrm{PM}_{10}$ in winter.

At the next stage of the investigation a comparison of the level of air pollution of settlements in which a different number of individual houses with coal-fired sources of heat supply was carried out. The village of Berezovka and the town of Zelenogorsk were chosen as these settlements. The distance between these localities is about $90 \mathrm{~km}$. The 506 apartment homes (http://gosjkh.ru/houses/krasnoyarskij-kraj/zelenogorsk) are in Zelenogorsk city. There are practically no individual houses. The 190 apartment buildings (http://gosjkh.ru/houses/krasnoyarskij-kraj/poselok-gorodskogo-tipaberezovka) and about 1700 single-storey houses (http://www.pgt-berezovka.ru/) are in the village of Berezovka. The vast majority of single-storey houses are heated by individual sources of heat.

Another circumstance contributed to the comparison of the level of pollution in two settlements. The dust analyzers of the VAM-1020 model were installed in the village of Berezovka and in the city of Zelenogorsk in November of 2017. The continuous measurements of the concentration of suspended particles have been carried out since November 11 of 2017. The concentration of $\mathrm{PM}_{2,5}$ is measured in the village of Berezovka and $\mathrm{PM}_{2,5}$ and $\mathrm{PM}_{10}$ is measured in the city of Zelenogorsk.

Average monthly PM concentrations are presented in Table 2 in the winter period. At the post of the city of Zelenogorsk the concentrations of $\mathrm{PM}_{2,5}$ and $\mathrm{PM}_{10}$ are measured for which the daily average value of MPC is $0,035 \mathrm{mg} / \mathrm{m}^{3}$ and 0,060 $\mathrm{mg} / \mathrm{m}^{3}$ respectively.

Table 2. Concentration of suspended particles $\left(\mathrm{mg} / \mathrm{m}^{3}\right)$ in the air of settlements in winter

\begin{tabular}{|l|c|c|c|c|c|c|}
\hline \multirow{2}{*}{} & \multicolumn{2}{|c|}{ December of 2017} & \multicolumn{2}{c|}{ January of 2018} & \multicolumn{2}{c|}{ February of 2018 } \\
\cline { 2 - 7 } & $\mathrm{PM}_{2,5}$ & $\mathrm{PM}_{10}$ & $\mathrm{PM}_{2,5}$ & $\mathrm{PM}_{10}$ & $\mathrm{PM}_{2,5}$ & $\mathrm{PM}_{10}$ \\
\hline Zelenogorsk & $0,030 \pm 0,002$ & $0,043 \pm 0,002$ & $0,034 \pm 0,002$ & $0,050 \pm 0,002$ & $0,027 \pm 0,0001$ & $0,044 \pm 0,001$ \\
\hline Berezovka & $0,036 \pm 0,001$ & & $0,051 \pm 0,002$ & & $0,067 \pm 0,002$ & \\
\hline
\end{tabular}

Table 2 shows that unlike the air environment of Zelenogorsk the atmosphere of the village of Berezovka is characterized by concentrations of PM above the hygienic standard in winter.

The dependences of the daily variation of the $\mathrm{PM}_{2,5}$ concentration during each winter month in the atmosphere of Zelenogorsk and Berezovka were determined during the investigation. These dependencies for the coldest month (January) are shown in Figures 5 and 6. The presence of extremes was established relative to the average monthly concentration of PM.

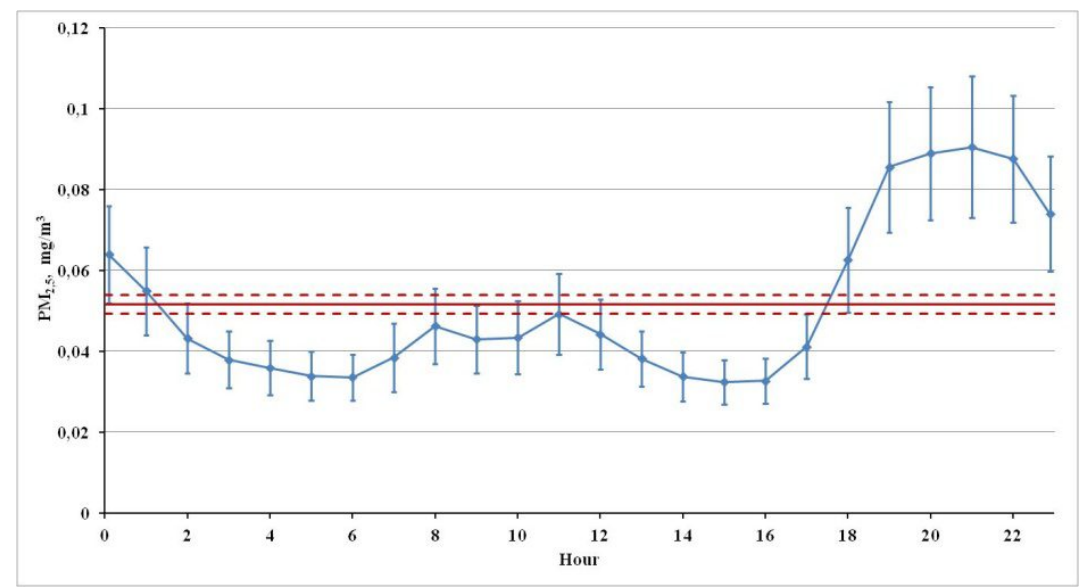

Figure 5. The daily variation of $\mathrm{PM}_{2,5}$ concentration in the atmosphere of the village of Berezovka in January of 2018. The brown line is the average monthly concentration of $\mathrm{PM}_{2,5}$, and the dotted lines represent the confidence interval of the deviation from the average monthly value 


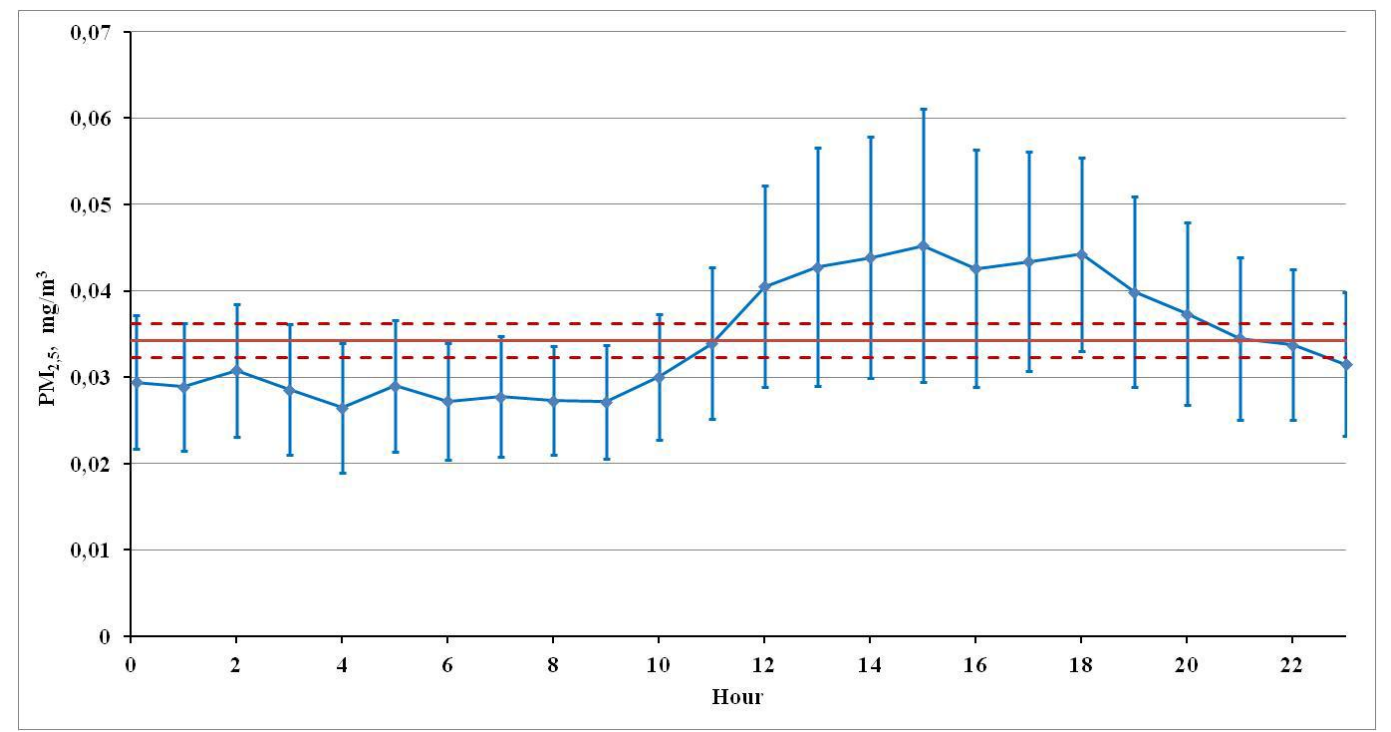

Figure 6. The daily variation of $\mathrm{PM}_{2,5}$ concentration in the atmosphere of Zelenogorsk in January of 2018. Designations as in Figure 5

The daily variation of the $\mathrm{PM}_{2,5}$ concentration in the atmosphere of the village of Berezovka is characterized by two authentically significant minima and one maximum (Fig. 5). The amplitude of the deviation from the monthly average value of the PM concentration at the maximum is almost twice as large as the amplitude deviations in the minima.

The reliably expressed extrema is not revealed in the daily variation of the concentration of $\mathrm{PM}_{2,5}$ in the atmosphere of Zelenogorsk (Fig. 6).

Only one reliable extreme appears in the daily variation of the $\mathrm{PM}_{10}$ concentration in the atmosphere of Zelenogorsk city. This is the minimum concentration of $\mathrm{PM}_{10}$ in the period of 4-6 hours (Fig. 7).

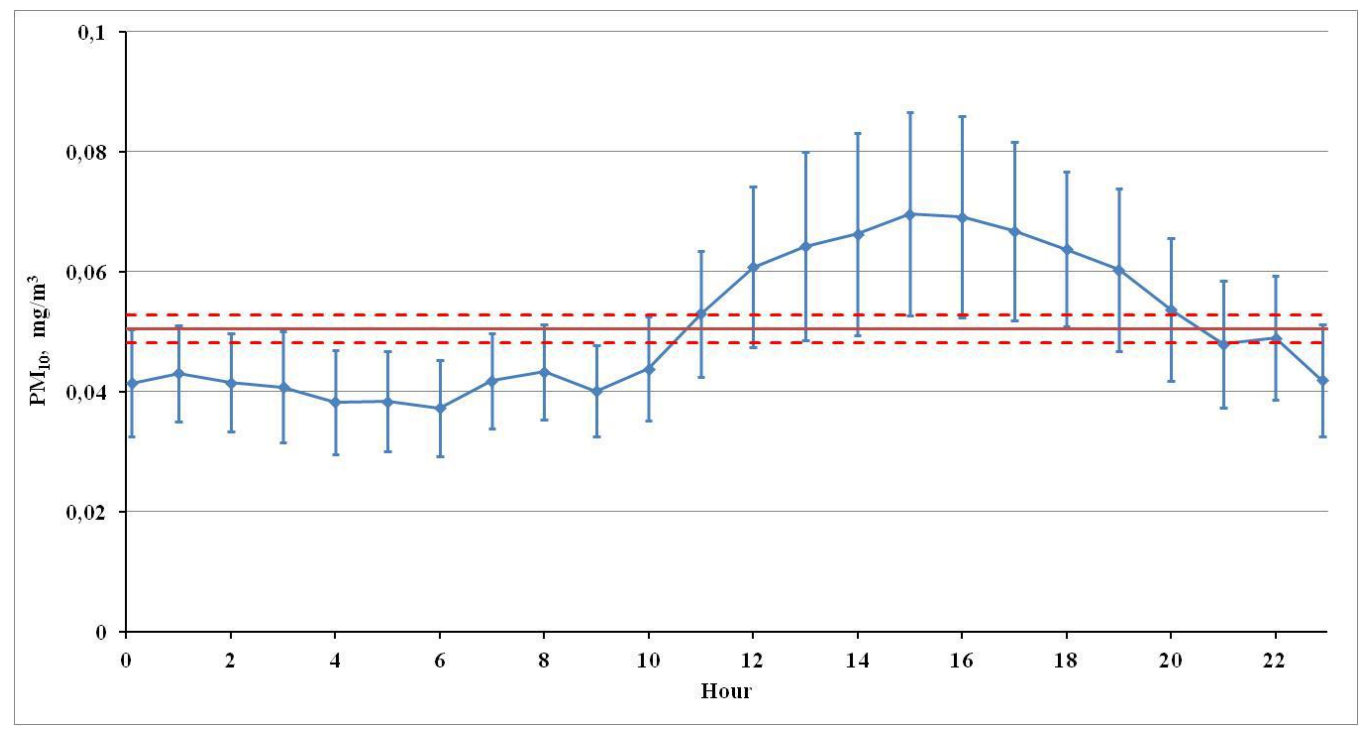

Figure 7. The daily variation of $\mathrm{PM}_{10}$ concentration in the atmosphere of Zelenogorsk in January of 2018. Designations as in Figure 5

Then the dynamics of diurnal changes in $\mathrm{PM}_{2,5}$ concentrations in the atmosphere of two settlements was compared. The average values for the entire winter period are shown in Figure 8. In the atmosphere of the village of Berezovka in comparison with the air environment of Zelenogorsk the pollution of the PM clearly shows up in the evening - 19-23 hours. It should be noted that the increase from the average level of PM concentration in the Zelenogorsk atmosphere is 
on 12-19 hours (Fig. 6 and 7). Different time intervals for the manifestation of the maximum contents of suspended particles in the air of two settlements indicate different reasons for their occurrence. One of the main differences of the considered settlements is that in Berezovka individual houses with different ASHS occupy about $80 \%$ of the territory of the village, and there are practically no such houses in Zelenogorsk. In fact there is a large-scale area source of PM emissions in Berezovka.

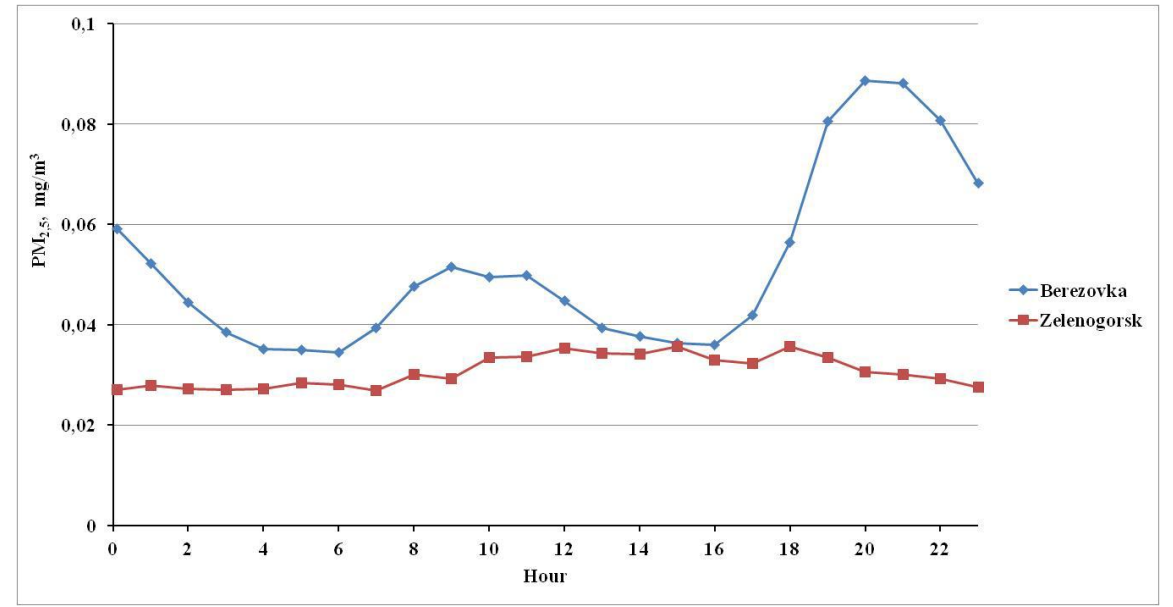

Figure 8. Average concentration of $\mathrm{PM}_{2,5}$ in the atmosphere of Zelenogorsk and Berezovka in winter

The main sources of PM which pollute the atmosphere in the settlements of Siberia are considered. These include: 1) industry, 2) coal-fired boilers, 3) motor transport, 4) ASHS.

The majority of industry enterprises (1) and heat power engineering (2) work continuously and their emissions are quasistationary in winter. Emissions from motor transport (3) and ASHS (4) are characterized by some periodicity.

The concentration of $\mathrm{PM}_{10}$ varies in a small range from 20-30 $\mu \mathrm{g} / \mathrm{m} 3$ to $30-40 \mu \mathrm{g} / \mathrm{m}^{3}$ in large megalopolises near transport highways where intensive traffic flows are observed [1]. There are no highways and traffic intensity as in megalopolises in the village of Berezovka. However the range of changes in concentration of $\mathrm{PM}_{10}$ is from $40 \mu \mathrm{g} / \mathrm{m}^{3}$ to $145 \mu \mathrm{g} / \mathrm{m}^{3}$ (Fig. 1); the range of changes in the concentration of $\mathrm{PM}_{2,5}$ is from $35-40 \mu \mathrm{g} / \mathrm{m}^{3}$ to $90-95 \mu \mathrm{g} / \mathrm{m}^{3}$ in winter (Fig. 5 and 8).

Consequently the main sources of PM emissions in the winter are ASHS which determine the daily dynamics of atmospheric pollution in the village (Fig. 9).

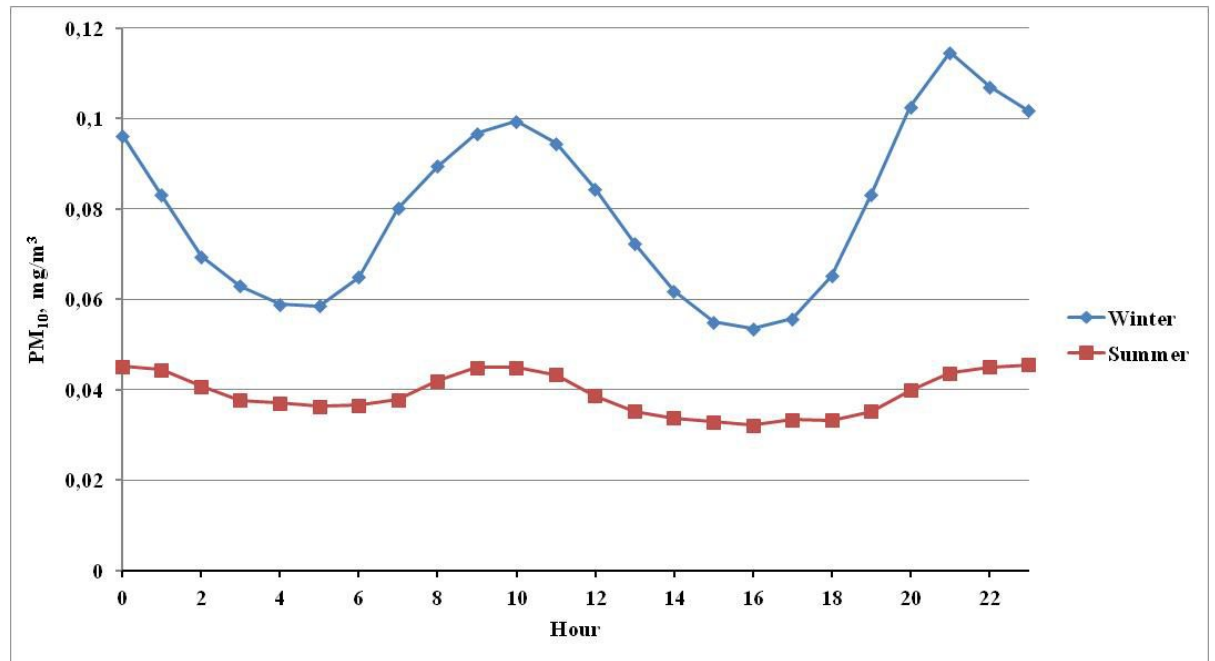

Figure 9. Average daily variation of $\mathrm{PM}_{10}$ concentration in the atmosphere of Berezovka village in summer and winter 
The clearly defined daily variation of the $\mathrm{PM}_{10}$ concentration in the winter period (Figure 9) is explained by the following circumstances. First, in the village of Berezovka ordinary furnace are mainly used as ASHS with the help of which in the cold period individual houses are heated twice a day - in the morning and in the evening. Second, brown coal is used for heating, when burning it many PM and other substances harmful to health are emitted into the atmosphere [2]. However the population uses coal as the most economically profitable fuel.

\section{REFERENCES}

[1] Glazkova, A. A., Kuznetsova, I. N., Shalygina, I. Yu. and Semutnikova, E. G. Daily course of aerosol concentration $\left(\mathrm{PM}_{10}\right)$ in the summer in the Moscow region, Optics of the atmosphere and ocean 25 (6), 495-500 (2012).

[2] Mukherjee, A., Agrawal, M. A. Global Perspective of Fine Particulate Matter Pollution and Its Health Effects, Rev. Environ Contam. Toxicol. 244, (2018).

[3] Zhang, R., Wang, G., Guo, S., Zamora, M.L., Ying ,Q., Lin, Y., Wang, W., Hu, M., Wang, Y. Formation of urban fine particulate matter, Chem. Rev. 115 (10), 3803-3855 (2015).

[4] Kuznetsova, I. N., Glazkova, A. A., Shalygina, I. Yu., Nechaev, M. I., Arkhangelsky, A. A., Zvyagintsev, M. A., Semutnikova, E. G., Zakharova, P. V. and Lezina, E. A. Seasonal and diurnal variability of concentrations of suspended particles in the surface air of residential areas of Moscow, Optics of atmosphere and ocean 27 (6), 473-482 (2014).

[5] Yausheva, E. P., Panchenko, M. V., Kozlov, V. S., Terpugova, S. A. and Chernov, D. G. The influence of the city on the aerosol characteristics of the atmosphere of Tomsk Akademgorodok in transitional seasons, Optics of atmosphere and ocean 27 (11), 981-988 (2014).

[6] Gubanova, D. P., Belikov, I. B., Elansky, N. F., Skorokhod, A. I. and Chubarova, N. E. Variability of surface concentration of $\mathrm{PM}_{2,5}$ aerosols in Moscow on observations in the Meteorological Observatory of Moscow state University, Optics of the atmosphere and ocean 30 (12), 1033-1042 (2017).

[7] Zavorueva, E. N., Zavoruev, V. V. and Pechenkin, F. A. concentration of suspended particles in the surface layer of the atmosphere of Krasnoyarsk in 2013-2016, Path of science 4 (38), 13-15 (2017). 